\title{
Optimal management of ulnar collateral ligament injury in baseball pitchers
}

This article was published in the following Dove Press journal:

Open Access Journal of Sports Medicine

II November 2015

Number of times this article has been viewed

\author{
Elizabeth E Hibberd' \\ J Rodney Brown ${ }^{2}$ \\ Joseph T Hoffer ${ }^{2}$ \\ 'Department of Health Science, \\ The University of Alabama, \\ Tuscaloosa, AL, USA; ${ }^{2}$ Department \\ of Intercollegiate Athletics, The \\ University of Alabama, Tuscaloosa, \\ AL, USA
}

\begin{abstract}
The ulnar collateral ligament stabilizes the elbow joint from valgus stress associated with the throwing motion. During baseball pitching, this ligament is subjected to tremendous stress and injury if the force on the ulnar collateral ligament during pitching exceeds the physiological limits of the ligament. Injuries to the throwing elbow in baseball pitchers result in significant time loss and typically surgical intervention. The purpose of this paper is to provide a review of current information to sports medicine clinicians on injury epidemiology, injury mechanics, injury risk factors, injury prevention, surgical interventions, nonsurgical interventions, rehabilitation, and return to play outcomes in baseball pitchers of all levels.
\end{abstract}

Keywords: ulnar collateral ligament, elbow injury, baseball, pitchers

\section{Injury epidemiology}

Baseball is one of the most popular sports in the USA with over 4.5 million participants annually and approximately $27,000-45,000$ collegiate baseball players. ${ }^{1-4}$ It has been reported that the minor league baseball has $\sim 1.79$ injuries per ten games, ${ }^{5}$ with an injury risk ratio of 1.09 per 1,000 athlete exposures for pitching. ${ }^{6}$ Collegiate baseball has reported 5.8 injuries per 1,000 athlete-game exposures and 1.9 injuries per 1,000 athlete-practice exposures. ${ }^{3}$ Baseball is considered to be a relatively safe sport with low injury rates. In comparison, collegiate American football has reported 35.9 injuries per 1,000 athlete-game exposures and 3.8 injuries per 1,000 athlete-practice exposures, and collegiate men's soccer has reported 18.8 injuries per 1,000 athlete-game exposures and 5.9 injuries per 1,000 athlete-practice exposures. ${ }^{7}$

Although the overall injury rate for baseball is low, $56 \%-75 \%$ percent of pitching injuries require time lost from sport. ${ }^{3,6,8}$ Of these pitching-related injuries, $25 \%$ are considered severe and require ten or more days lost from sport. ${ }^{3}$ Despite considerable improvements in diagnostic measures, conditioning, and surgical procedures, Major League Baseball (MLB) still shows an increasing trend in injuries to pitchers. ${ }^{6,8}$

With baseball, especially pitching, a large number of injuries and lost time are attributed to upper extremity injuries such as impingement, rotator cuff injury, shoulder instability, labral tears, and elbow ulnar collateral ligament (UCL) injury. ${ }^{3,5,6,8-12}$ Upper extremity injuries account for $67 \%$ of all injuries to pitchers and over 74 days on the disabled list in the Major Leagues. ${ }^{6}$ Also in the Major Leagues, pitchers account for almost half of all disabled list reports, with shoulder and elbow injury accounting for almost half of the days on the disabled list. $^{8}$ In collegiate baseball, shoulder and elbow pain account for $36 \%$ of complaints and missed days. ${ }^{11}$ In little league, almost half
Correspondence: Elizabeth E Hibberd Department of Health Science, The University of Alabama, 483 Russell Hall, Box 8703।I, Tuscaloosa, AL 35487-03। I, USA Tel + I 2053487320

Email eehibberd@ches.ua.edu 
of all pitchers report elbow or shoulder pain at some point during a baseball season..$^{9,10}$

Based on MLB injury data, injuries to the throwing elbow accounted for $\sim 16 \%$ of all injuries in baseball players and $25 \%$ of all injuries in pitchers. ${ }^{6,13}$ Other prevalent injuries on body parts in baseball pitchers are the shoulder $(21 \%)^{6}$ and knee (17\%). ${ }^{13}$ These injuries resulted in an average of 27 days missed per injured player in all players and 39 days missed per injured pitcher. ${ }^{13}$ In collegiate baseball, 4.5\% of injuries in baseball players were reported as ligament sprains. ${ }^{3}$ Although there is not a complete injury database for elbow injuries in baseball athletes of high school aged and younger, clinical evidence from the American Sports Medicine Institute has suggested a significant increase in UCL tears in this younger population. Between 1994 and 1998 , only $7 \%$ of UCL reconstructions were performed on this younger population; however, by 2004-2008, 26\% of UCL reconstructions at their clinic were performed on high school aged or younger patients. ${ }^{14}$ These increases in injury rates may be due to increase or changes in training methods, participation, or diagnostic capabilities.

\section{Injury mechanics}

The UCL stabilizes the elbow joint from valgus stress associated with the throwing motion. When the elbow is flexed, the UCL provides $\sim 54 \%$ of the internal varus torque. ${ }^{15}$ During the cocking phase of pitching, the elbow experiences significant valgus stress. Youth pitchers experience $\sim 28 \mathrm{Nm}$ of valgus stress, high-school pitchers experience $\sim 48 \mathrm{Nm}$ of valgus stress, college pitchers experience $\sim 55 \mathrm{Nm}$ of valgus stress, and professional players experience $64 \mathrm{Nm}$ of valgus stress. ${ }^{16}$ In a cadaveric study, the UCL was found to only be able to resist $\sim 32 \mathrm{Nm}$ of valgus stress. ${ }^{17}$ This finding has been used extensively in the literature to support the premise that each pitch experiences near-failure tensile stress or exceeds the capabilities of the ligament emphasizing the importance of dynamic stabilizers. ${ }^{15,16,18,19}$ These findings should be interpreted with caution, as these findings were never published beyond the abstract presentation.

While the ultimate strength of the UCL has not been clearly identified in the literature, it is well documented that the UCL resists a tremendous amount of valgus stress during the pitching motion. The cumulative microtrauma of repetitive near-failure tensile stress leads to UCL tears and failure. ${ }^{16,18-20}$ Previous research studies have identified an increase in joint laxity ${ }^{21,22}$ and a decrease in peak force of the ligament ${ }^{23}$ following repeated subfailure loads. Accumulation of microtrauma to the UCL leads to a reduction in the ultimate tensile load that the ligament can withstand and increases the risk of failure. UCL tears are most commonly caused by the cumulative microtrauma associated with throwing followed by a single throw, resulting in a popping or tearing sensation and medial elbow pain. ${ }^{24}$ In $76 \%$ of patients with UCL tears, heterotropic calcification was found in the UCL, indicating ossification in the ligament due to chronic stress and accumulation of microtrauma following subfailure loading during the throwing motion. ${ }^{25,26}$ Further, the dynamic stabilizers of the elbow are also experiencing microtrauma and/or fatigue and may not be as able to help attenuate the valgus stress at the elbow and ultimately increasing the valgus stress that the UCL is required to resist.

\section{Risk factors}

Because of the significant disability and time loss that occurs following UCL injuries, researchers and clinicians have worked to identify risk factors of injury in order to develop screening tools and preventative interventions. Although significant research has been conducted, there is still limited conclusive evidence on prospective risk factors of injury. This review will identify risk factors that have been proposed by clinicians and provide a discussion of the available research evidence on these proposed risk factors.

\section{Pitch count}

Repetitive throwing causing microtrauma without adequate time for recovery has been proposed as a risk factor for UCL tears. ${ }^{24,27}$ Media and parents of younger players often blamed high pitch counts as the cause for injury. In youth baseball players, higher pitch counts have been associated with increased risk of shoulder and elbow pain. ${ }^{9,10}$ Olsen et $\mathrm{al}^{28}$ found that higher number of warm-up pitches, more innings pitched per game, more pitches thrown per game, and pitching eight or more months out of the year were associated with a higher risk of elbow injuries in youth baseball pitchers. The risk of elbow pain increases by $6 \%$ for every ten pitches thrown and increases $50 \%$ when greater than 75 pitches are thrown. ${ }^{10}$ This elbow pain that is experienced in youth baseball players is indicative of microtrauma. Overtime, this microtrauma can lead to attenuation of the UCL and/or ossification within the UCL increases the risk of failure of the UCL. ${ }^{16,26}$

While the evidence in youth and high school baseball suggests that high pitch counts may be a risk factor for UCL injury, high pitch counts have not been clearly identified as a risk factor for injury in collegiate and MLB pitchers. In collegiate baseball pitchers, significant alterations in pitching mechanics and elbow and shoulder kinetics were not observed 
in a simulated game where all pitchers threw between 105 and 135 pitches. ${ }^{29}$ In collegiate baseball players, the evidence does not support the fact that single-game pitch counts significantly increase the risk of UCL injury. Total appearances, total innings pitched, total pitches thrown, innings pitched per appearance, pitches per appearance were not significantly associated with the injury in MLB pitchers. ${ }^{30}$ While this study was not specific to UCL injuries, it does provide evidence that work metrics alone are not sufficient for predicting and preventing injury in elite pitchers. In addition, single game and cumulative pitch counts have not been linked to meaningful changes in pitching performance. ${ }^{31}$

Participation factors in little league baseball have been identified as risk factors for elbow injury; however, a significant relationship between pitch count and injury in physically mature, elite baseball players has not been established in the literature. Research on participation factors and the underlying physiological mechanisms during and following participation is needed to fully understand the role of pitch counts/work metrics and how these can be used in baseball at different levels.

\section{Pitch velocity}

In addition to repetitive throwing, pitching velocity has been associated with elbow injury. ${ }^{32}$ In a group of professional baseball pitchers, high-velocity pitching was significantly associated with elbow injury and the need for surgical intervention to treat the elbow injury. ${ }^{32}$ During late cocking and acceleration phases of pitching, the increased stress on the elbow with higher velocity pitching may overcome the tensile strength of the UCL, resulting in failure of the UCL. In competitive high school baseball pitchers, pitching velocity was associated with increased stress on the medial elbow; ${ }^{33}$ however, pitching velocity was not associated with medial elbow stress in collegiate baseball players. ${ }^{34}$ The influence of velocity of pitching on elbow kinetics is still an area that needs further exploration.

In minor league baseball, fastball pitching velocity increased over an eight-game period and there were no effects of cumulative number of pitches thrown, innings pitched, rest days, and pitching work to rest ratios on fastball velocity. ${ }^{35}$ The relationship between pitch velocity and participation variables should be further investigated at different levels of baseball participation.

\section{Pitching mechanics}

The pitching motion is a complex movement that generates tremendous force and places significant strain on the soft-tissue restraints of the upper extremity. ${ }^{16}$ Although significant research and practice time are focused on evaluating pitching mechanics, proper pitching mechanics have not been clearly identified in the literature. The idea of "good pitching form" is conceptual and is often coach- and athlete-dependent. Although perfect mechanics have not been established, there are certain mechanics that increase the valgus stress at the elbow, thus increasing the risk of a UCL injury. Increased valgus stress at the elbow during pitching has been found in baseball pitchers with greater maximum shoulder external rotation angle, smaller elbow flexion (more extension) at peak valgus torque, late lateral trunk rotation, $>10^{\circ}$ contralateral trunk lean, and a sidearm delivery. ${ }^{36-38}$ The increase in valgus torque at the elbow with one or a combination of these deviations can lead to microtrauma or macrotrauma of the UCL.

Interestingly, some of the pitching mechanics that have been reported to increase elbow joint stress also are associated with greater throwing velocity. Specifically, greater shoulder external rotation range of motion was found in collegiate pitchers who were classified as high-velocity pitchers (mean $>85 \mathrm{mph}$ ) compared to low-velocity pitchers (mean $<76.5 \mathrm{mph}$ ). ${ }^{39}$ Greater shoulder external rotation has been hypothesized to increase the stored elastic energy of the internal rotators and improve the stretch-shortening cycle, increasing the concentric strength of the internal rotators during the acceleration phase of pitching, thus ultimately increasing pitching velocity. ${ }^{39,40}$ In addition, excessive contralateral trunk tilt has been associated with greater pitching velocity. ${ }^{38}$ The authors of this study suggest that increased contralateral trunk tilt indirectly increases maximum shoulder external rotation, which results in a greater pitching velocity. Continued research is needed in order to maximize performance while minimizing injury risk.

\section{Pitch type}

Although the curveball has historically been considered a dangerous pitch for youth athletes, research studies evaluating pitching mechanics, kinetics, and incidence of injury do not suggest an increased injury risk of the curveball compared to a fastball. ${ }^{41}$ Proper mechanics are critical to injury prevention, independent of pitch type, and considerable time should be spent teaching proper mechanics for both decreased injury risk and improved performance.

\section{Range of motion}

As a result of repetitive throwing, adaptations in glenohumeral range of motion occur. Adaptations in glenohumeral range 
of motion have been linked to an increased risk in UCL tears. ${ }^{42-44}$ Glenohumeral internal rotation deficit (GIRD) is defined as the loss of internal rotation range of motion of the throwing shoulder compared to the nonthrowing shoulder. ${ }^{45}$ GIRD has previously been found to increase the risk of UCL tears. ${ }^{42}$ In baseball players with UCL insufficiency, Dines et al $1^{42}$ found that injured athletes had $28.5^{\circ}$ of GIRD, while healthy controls had $12.7^{\circ}$ of GIRD. These authors suggested that pathological GIRD increases valgus instability, challenging the physiological limits of the UCL. Recent studies have reported that evaluating side-to-side differences in total glenohumeral rotation range of motion (external rotation + internal rotation) may be more informative with regard to UCL injuries than evaluation in only one direction. ${ }^{43,44}$ A cross-sectional study found that baseball players with UCL tears had $\sim 7^{\circ}$ difference in total rotational range of motion, while uninjured athletes had only a $1^{\circ}$ difference between sides. In a prospective analysis of glenohumeral passive range of motion variables on risk of elbow injury in professional baseball pitchers, Wilk et a ${ }^{44}$ observed a 2.6 times greater injury risk in those pitchers that had a total range of motion deficit of $5^{\circ}$ or more. Alterations in rotational range of motion in baseball players occur as a result of repetitive throwing and microtrauma to stabilizing structures. These alterations may cause changes in biomechanics and kinetics during throwing and challenge the physiological limits of the UCL.

Humeral retrotorsion is an osseous contributor to measured rotation range of motion. ${ }^{46-49}$ Humeral retrotorsion represents the amount that the distal humerus is twisted relative to the proximal humerus. The contribution of humeral retrotorsion to humeral rotation range of motion may especially be large in overhead athletes, given the torsional moments that are placed on the humerus during the act of throwing. ${ }^{50}$ Previous research has found that baseball players who display with GIRD have greater humeral retrotorsion on the dominant limb. ${ }^{51}$ Further, increases in GIRD as youth baseball players mature can be attributed to increases in humeral retrotorsion, rather than increased soft-tissue tightness. ${ }^{52}$ As previously discussed, GIRD is a risk factor for UCL tears, thus the presence of humeral retrotorsion leading to GIRD may be a risk factor for elbow injury. Additionally, the dominant limbs of throwing athletes repeatedly show more humeral retrotorsion, shifting the glenohumeral rotation arc toward the external rotation direction, thus decreasing internal rotation. ${ }^{46-48,53,54}$ This shift toward greater external rotation range of motion may increase the valgus torque on the elbow, ultimately increasing the risk of failure of the UCL. ${ }^{16,55}$

\section{Injury prevention}

Prevention of injury to the UCL is focused on addressing the risk factors for injury. It is clear in the literature that participation factors are the greatest risk factor for injury. The USA Baseball Medical and Safety Advisory board combined research evidence with clinical expertise to create participation recommendations for youth and high school baseball players. ${ }^{56}$ These guidelines specify outing, weekly, season, and year pitching limits. For example, pitchers between the ages of 13 and 14 should pitch no more than 75 pitches per outing, 125 pitches per week, 1,000 pitches per season, and 3,000 pitches per year. ${ }^{56}$ The USA Baseball Medical and Safety Advisory Committee also recommends that youth pitchers do not throw more than 100 innings in a year and take at least 2-4 months off of baseball participation each year. ${ }^{56}$ Little League baseball guidelines allow pitchers to throw more pitches a game and there are no weekly, seasonal, and yearly pitch guidelines. For example, a 13-16 year old is allowed to throw 95 pitches per game. ${ }^{57}$ Little League baseball guidelines do not allow a pitcher who has thrown over 41 pitches to play catcher on the same day. ${ }^{57}$ This recommendation is supported by findings that pitchers who also played catcher were more likely to be injured. ${ }^{27}$ While it is important for pitchers to play different positions, the large volume of throwing at the catcher position may further exacerbate the stress on the shoulder and elbow and increase the risk of injury. Playing a traditional infield or outfield position may decrease the risk of injury.

In addition to monitoring of throwing limits, allowing the appropriate amount of time for recovery is recommended. Recommendations for days of rest are based on pitch counts per pitching outing; 1 day of rest with 30 pitches thrown, 2 days with 40 pitches, 3 days with 60 pitches, and 4 days with 90 pitches thrown for ages $17-18 .{ }^{57}$

There are no guidelines in collegiate or major league pitch limits or days of rest as no clear evidence to date that identifies a significant relationship between traditional measures of pitching workload (ex pitch counts) and injury risk. In collegiate baseball, each starting pitcher traditionally pitches one time a week. With Major Leaguers, there has been a trend toward lower pitch counts and five-man pitching rotations in recent years. It is common practice to limit a starting pitcher to 100 pitches per outing and to pitch every 5 days or 6 days. ${ }^{58}$

Evaluation of pitching mechanics is another method for injury prevention. While standardized proper pitching mechanics have not been clearly identified in the literature, it is important that pitching mechanics that decrease valgus 
stress on the elbow are taught and utilized in youth baseball. While the most accurate pitching mechanics assessments occur in high-tech laboratories, a simple assessment of pitching mechanics can be performed using video analysis. Davis et al ${ }^{59}$ identified five parameters that can be evaluated on video analysis such as leading with the hips, hand on-top position, arm in throwing position (elbow at max height at stride foot contact), closed-shoulder position, and stride foot toward home plate. Youth pitchers that perform three or more of these parameters correctly display lower elbow valgus load, thus decreasing the stress on the UCL. ${ }^{59}$ In addition, serial evaluations at all levels of baseball can also serve as an indicator of changes that are occurring in the pitching motion due to fatigue or injury and may provide valuable information to the coach and clinician.

Finally, maintaining glenohumeral range of motion and scapular functioning is essential to injury prevention. Loss in internal rotation range of motion is partially caused by posterior shoulder tightness. Stretching of the posterior shoulder structures will improve range of motion and decrease the risk of injury. Stretching of the posterior shoulder can be accomplished through a regular stretching program such as the sleeper stretch, modified sleeper stretch, and cross-body stretch. ${ }^{60-62}$ In addition to a regular stretching program, a strengthening program that focuses on scapular stabilization and shoulder strength should be performed regularly. The most common programs used in baseball are the Thrower's Ten or the Advanced Thrower's Ten. ${ }^{63,64}$ Maintaining normal range of motion, scapular control, and shoulder strength will decrease the stress on the medial elbow and decrease the risk of UCL tear.

\section{Interventions}

Treatment options following an injury to the UCL are either a conservative, nonsurgical intervention, or surgical intervention. Nonsurgical interventions are often used for intact continuity or low-grade partial tears. ${ }^{19}$ Surgical interventions are typically used on high-grade partial tears or a complete tear of the UCL. ${ }^{19}$ On examination, surgery was recommended in individuals with a partial tear in $>50 \%$ of the ligament substance and/or in those with fluid-like high-signal intensity of the injured UCL with extension to the articular surface or the medial margin of the coronoid on fat suppressed T2 weighted fast spin echo magnetic resonance images. ${ }^{19}$ Failure of nonsurgical treatment in baseball players was found in individuals with a complete UCL tear, those with a residual ossicle in the UCL, and those with symptomatic ulnar nerve disorders. ${ }^{65}$

\section{Nonsurgical intervention}

Nonsurgical interventions are typically split into two phases. During Phase I, the patient is treated symptomatically. The goal of this phase is to manage pain and inflammation and restore normal range of motion. Acutely, range of motion should be limited to $10^{\circ}-100^{\circ}$ of elbow flexion and increased gradually over the next 3-4 weeks. ${ }^{66}$ Once symptoms have resolved and full range of motion is achieved, a progressive strengthening program can begin. Initial strengthening exercises should focus on strengthening of the core and shoulder musculature to help attenuate forces at the elbow and rhythmic stabilization of the upper extremity to emphasize strength, dynamic stabilization, and neuromuscular control. In addition, strengthening of the flexor-pronator muscle mass should be emphasized. As a group, the flexor-pronator muscle mass provides significant varus moment to resist the valgus stress at the elbow. ${ }^{67-69}$ In particular, the flexor carpi ulnaris ${ }^{67,68}$ and the flexor digitorum superficialis ${ }^{69}$ have been found to provide the greatest contributions to varus moment. The focus on strengthening the flexor-pronator muscle mass will improve the dynamic stability of the elbow against valgus stress.

More advanced strengthening can begin 6-7 weeks following injury. A strengthening program, such as Thrower's Ten, has previously been recommended for use in dynamic strengthening of the upper extremity in baseball players. ${ }^{63}$ Several other programs that emphasize dynamic strength through plyometrics, core stabilization, open and closed kinetic chain exercises have been found to be effective at strengthening and/or improvements in performance. ${ }^{70-72}$ Once the athlete demonstrates pain-free movement with full strength and range of motion, an interval throwing program can be initiated. An interval throwing program is imperative to the success of the rehabilitation program to allow the tissues to be appropriately stressed and give adequate time for recovery. Data-driven throwing programs have been developed and used clinically based on competition level and position. ${ }^{73}$ If pain or a feeling of instability is reported during the throwing program, the athlete should be referred to discuss possible surgical intervention. Once returned to full activity, continued strengthening and stretching, as well as strict pitching limits with time for recovery, should be enforced.

\section{Nonsurgical intervention outcomes}

In NFL quarterbacks, nonsurgical treatment of UCL injuries (grades 1-3) has been shown to be effective with $9 / 10$ quarterbacks with a mean return to play of 26.4 days. ${ }^{74}$ 
While the throwing motions between quarterbacks and other throwing athletes may be similar, quarterbacks utilize more horizontal adduction and elbow flexion during the cocking phase, while baseball players displayed greater external rotation. ${ }^{75}$ These differences in throwing kinematics will influence the stress on the UCL, with greater stress on the UCL during baseball pitching. While conservative treatment of the UCL in football quarterbacks may be an effective treatment, success rates of nonoperative treatment in other throwing athletes have not been found to have similar success rates due to greater stress placed on the UCL. In a group of throwing athletes with UCL tears (20 pitchers, nine infielders, and two javelin throwers), only $42 \%$ were able to return to their sport at the level they were playing prior to injury with an average return to play time of 24.5 weeks. ${ }^{76}$ In 39 baseball players with injuries to the UCL, 12 were successfully treated with rehabilitation, and of the 12 that were treated nonoperatively, eight were able to return to baseball participation. ${ }^{19}$ This indicates a $67 \%$ success rate in those where conservative treatment was tried and an overall rate of $21 \%$ of athletes with a UCL injury able to return to play with no surgical intervention. ${ }^{19}$ Furushima et $\mathrm{al}^{77}$ reported an $82 \%$ success rate of treating a partial UCL tear with conservative treatment, but only $33 \%$ of baseball players treated nonoperatively could return to pitching. Conservative treatment may be considered in baseball athletes with a partial UCL tear with no ulnar nerve symptoms or bony abnormalities; however, the return to full participation in baseball and especially pitching is low.

\section{Surgical interventions}

Surgical repair of the UCL is most often indicated in grade 2 or 3 tears. In 1974, Dr Frank Jobe performed UCL reconstruction on a MLB player named Tommy John. This was the first documented successful repair of the UCL and allowed Tommy John to continue in his baseball career. Since that time, "Tommy John" surgery has become the common name for a UCL reconstruction. Jobe et $\mathrm{al}^{78}$ described the original procedure for UCL reconstruction in 1986, and this procedure continues to be used today. In this procedure, the flexor-pronator muscle mass is detached from its attachment on the medial condyle, while a submuscular ulnar nerve transposition is performed, and function of the anterior band of the UCL is restored by drilling bone tunnels and weaving figure-of- 8 graft at the medial elbow. ${ }^{78}$

Since this first successful surgery and subsequent description of the procedure, there have been a variety of modifications to this procedure proposed with the most common techniques being the Andrews Sports Medicine Institute (ASMI) technique, ${ }^{79}$ modified Jobe technique with musclesplitting, and the docking technique. The ASMI technique was developed by Dr James Andrews at the Andrews Sports Medicine Institute. The ASMI technique is a modification of the Jobe technique where the flexor-pronator muscle mass is reflected medially and a subcutaneous ulnar nerve transposition is performed. ${ }^{79}$ The modified Jobe technique with muscle splitting was first introduced by Smith et al. ${ }^{80}$ In this technique, the posterior $1 / 3$ of the flexor-pronator muscle mass was split, rather than reflected, to provide visibility of the UCL and bony landmarks. In addition, an ulnar nerve transposition was not described as standard practice. In 2002, the docking technique was introduced by Rohrbough et al. ${ }^{81}$ This modification of the original Jobe technique utilizes the muscle splitting technique with the graft being docked into a single-humeral tunnel. ${ }^{82}$

Several studies have been done to compare the postsurgical outcomes following UCL reconstruction. One metaanalysis reported that the overall complication rate following UCL reconstruction was $18.6 \%$, with the highest complication rate when the Jobe technique was used (29.2\%) and the lowest complication rate occurring with the modified docking technique and docking technique ( $2 \%$ and $6 \%$, respectively). ${ }^{83}$ It has been reported that using a muscle splitting technique leads to improved outcomes. ${ }^{84}$ An ulnar nerve transposition should only be performed if symptoms indicate ulnar nerve involvement. ${ }^{84}$ Ultimately, the surgical technique depends on the surgeon's expertise, prior experience, and preference.

In addition to the surgical technique used, graft type is another consideration during UCL reconstruction. In Jobe's original report of the surgical technique, the palmaris longus was used in $75 \%$ of the cases, with the plantaris or a strip of the Achilles tendon being used as the donor tendon in the other $25 \%$ of cases. ${ }^{78}$ The palmaris longus continues to be the most frequently used donor tendon with more recent studies reporting the palmaris longus as the donor tendon in $70 \%-75 \%$ of UCL reconstructions and the gracilis being the second most common donor tendon. ${ }^{85,86}$ It has previously been reported that the reconstructed UCL using a palmaris longus graft was as strong or stronger than the native UCL. ${ }^{87,88}$ More recent evidence has suggested that the reconstructed UCL using a palmaris longus is weaker than the native UCL; however, there are no differences between the strength of different graft types (palmaris longus, gracilis, and patellar tendon). ${ }^{89}$

While an autograft donor tendon has traditionally been used, a recent study has suggested the use of a hamstring 
allograft for UCL reconstruction..$^{90}$ Using an allograft would decrease complications that occur from harvesting the autograft, which have previously been reported to occur in $\sim 4 \%$ of UCL reconstructions. ${ }^{85}$ Savoie et $a{ }^{90}$ reported that of their 116 athletes who underwent a UCL reconstruction using a hamstring allograft, $95 \%$ of the athletes had returned to play within 2 years of the surgery. While the use of allograft donor tendons is not widely reported in the literature, outcomes of the hamstring allograft are similar to what is reported in the literature for the autograft techniques. ${ }^{90}$ This graft selection warrants more research, as it may help to decrease complications following surgery.

Following UCL reconstruction, it is imperative that the rehabilitation plan presented by the surgeon is followed. The most comprehensive rehabilitation protocol has been described by Kevin Wilk from ASMI and is considered the gold standard for rehabilitation programs. ${ }^{66}$ This program is split into four distinct phases: immediate motion, intermediate, advanced strengthening, and return to activity. During Phase I (immediate motion), the focus should be on decreasing pain and inflammation, regaining full extension, and beginning isometric exercises ${ }^{66} \mathrm{~A}$ biomechanical study of strain on the UCL during rehabilitation following $\mathrm{UCL}$ reconstruction reported that elbow flexion beyond $50^{\circ}$ increases stress on the reconstructed UCL, but full extension and isometric exercises are safe to perform. ${ }^{7}$ During Phase II (intermediate), full range of motion should be restored and a strengthening program of the scapular stabilizers, such as Thrower's Ten, and neuromuscular control exercises should be initiated. ${ }^{63,66}$ Phase III (advanced strengthening) focuses on sport specific strength and improving functional capabilities. An Advanced Thrower's Ten program has been developed, that focuses on coordination, neuromuscular control, and dynamic stabilization that will be necessary when the athlete returns to throwing. ${ }^{64}$ In addition, core and lower extremity strengthening and flexibility should be emphasized during this phase. The throwing motion in baseball is a complex task that is accomplished through transfer of energy from the lower extremity to the upper extremity through the kinetic chain. A break in the kinetic chain, due to lower extremity or core weakness or tightness, can increase the stress at the shoulder and elbow and increase the risk for reinjury. ${ }^{92,93}$ Finally, the last phase of rehabilitation is Phase IV (return to sport). This phase involves a progressive return to throwing and should utilize an established interval throwing program. ${ }^{73,94}$ Full return to throwing is estimated to take 11.6 months following UCL reconstruction. ${ }^{85}$ During rehabilitation, the patient should be monitored for the presence of pain and/or inflammation, and the rehabilitation program should be adjusted. Each rehabilitation following UCL reconstruction is unique. Changes and advancements in rehabilitation should be based on athlete presentation, not on predefined time guidelines. A comprehensive and deliberate rehabilitation program is imperative to a successful return to play and avoiding longterm complications.

\section{Surgical intervention outcomes}

Surgical repair of the UCL has been found to have good outcomes in baseball players. The majority of work on outcomes following UCL repair has been conducted in MLB. Erickson et al ${ }^{95}$ evaluated the outcomes of 179 MLB pitchers who underwent UCL reconstruction between 2010 and 2013. In this cohort of UCL reconstructed pitchers, $83 \%$ of the individuals returned to pitching in MLB and 97.2\% returned to pitching in either the MLB or minor leagues..$^{95}$ Fleisig et a ${ }^{96}$ evaluated minor league baseball pitchers with a history of UCL reconstruction and compared range of motion and biomechanical parameters to healthy control subjects who did not have a history of shoulder or elbow surgery. There were no significant differences between the reconstructed UCL and controls on glenohumeral range of motion and elbow or shoulder angle, velocity, torque, or force. ${ }^{96}$ Despite reconstruction, biomechanical parameters did not change, thus decreasing the risk of subsequent injury. Further, it has been reported that there were no significant differences in pitching performance variables between MLB pitchers who underwent UCL reconstruction and healthy controls.$^{65}$ There were no statistically significant differences between pitchers who underwent UCL reconstruction and healthy controls on pitch velocity, earned run average (ERA), batting average against, walks per nine innings, strikeouts per nine innings, and walks plus hits per inning pitched. ${ }^{65}$ Other studies have reported improved pitching performance following UCL reconstruction, with a reported lower losing percentage, decreased ERA, less walks and hits per inning pitched following reconstruction.${ }^{95}$ Overall, outcomes following UCL reconstruction indicate that baseball players can return to full participation with similar biomechanical profiles as uninjured pitchers with performance levels similar to or better than uninjured controls. While innings pitched in the first season back following reconstruction may be decreased compared to controls, normal workload returns by the second full season back. ${ }^{65}$

Research is limited on outcomes following UCL reconstruction in high school and collegiate baseball; however, the 
limited evidence suggests that outcomes are similar to the reported outcomes in MLB players. In high school baseball, $74 \%$ of UCL reconstructed players (20/27) returned to playing baseball at the same or higher level. ${ }^{24}$ Of the seven individuals who did not return to playing baseball at the same level or higher, only two of these individuals retired due to pain in their elbow from baseball participation. The other individuals retired due to graduation, pursuing other interests, or other injuries. When asked after rehabilitation and clearance for full participation, $100 \%$ of these individuals reported that they would have surgery again. More research is needed to evaluate return to pitching performance and revision rate in high school baseball.

In $\sim 1 \%$ of UCL reconstructions, a revision surgery is necessary when pain, stiffness, and/or ulnar nerve symptoms prevent the athletes from throwing or competing. ${ }^{85,97}$ The average time from initial reconstruction surgery to revision surgery was 36 months in a group of high-level baseball players. ${ }^{97}$ In one study of competitive baseball players, $43 \%$ had an excellent outcome and were able to return to their preinjury level of play, while the other $57 \%$ were not able to reach their preinjury level of play and either played at a lower level, played recreational, or were unable to return at any level. ${ }^{97}$ In a group of 18 MLB players who underwent a revision of their $\mathrm{UCL}$ reconstruction, $78 \%$ were able to return to pitching in the MLB within two seasons. ${ }^{98}$ Although these pitchers were able to return to playing, starters were only able to pitch at $35 \%$ of their prior workload, and relief pitchers were only able to pitch at $50 \%$ of their preinjury workload. ${ }^{98}$

\section{Conclusion}

Injuries to the UCL in baseball players occur due to the incredible stress that is placed on them while resisting valgus stress. When overuse, fatigue, poor mechanics, and/ or altered physical characteristics are present, there is an increased risk of injury. Pitch limits, adequate recovery, avoidance of specific pitching errors, and full glenohumeral range of motion may be employed as methods of reducing the risk of injury. Risk factors identified in the literature differ based on the level of competition, thus injury prevention strategies should be specific to competition level. If an injury to the UCL does occur, nonoperative or operative rehabilitation can be utilized. Operative treatment through a UCL reconstruction is shown to have better outcomes than nonoperative treatment and provides the pitcher the best opportunity to return to full participation with limited lasting symptoms or complications.

\section{Disclosure}

The authors report no conflicts of interest in this work.

\section{References}

1. USA Baseball Final Report [Webpage on the Internet] Catastrophic Injuries in USA Baseball 1989-2006; 2009. Available from: http://web. usabaseball.com/downloads/2009/final_report.txt. Accessed November 3, 2015.

2. Shanley E, Rauh MJ, Michener LA, Ellenbecker TS. Incidence of injuries in high school softball and baseball players. JAthl Train. 2011; 46(6):648-654.

3. Dick R, Sauers EL, Agel J, et al. Descriptive epidemiology of collegiate men's baseball injuries: National Collegiate Athletic Association Injury Surveillance System, 1988-1989 through 2003-2004. J Athl Train. 2007; 42(2):183-193.

4. Seefeldt VEM, Walk S. Overview of Youth Sports Programs in the United States. Washington, DC: Carnegie Council on Adolescent Development; 1992.

5. Chambless KM, Knudtson J, Eck JC, Covington LA. Rate of injury in minor league baseball by level of play. Am J Orthop. 2000;29(11): 869-872.

6. Posner M, Cameron KL, Wolf JM, Belmont PJ Jr, Owens BD. Epidemiology of Major League Baseball injuries. Am J Sports Med. 2011;39(8):1676-1680.

7. Hootman JM, Dick R, Agel J. Epidemiology of Collegiate Injuries for 15 sports: Summary and Recommendations for Injury Prevention Initiatives. J Athl Train. 2007;42(2)311-319.

8. Conte S, Requa RK, Garrick JG. Disability days in major league baseball. Am J Sports Med. 2001;29(4):431-436.

9. Lyman S, Fleisig GS, Andrews JR, Osinski ED. Effect of pitch type, pitch count, and pitching mechanics on risk of elbow and shoulder pain in youth baseball pitchers. Am J Sports Med. 2002;30(4):463-468.

10. Lyman S, Fleisig GS, Waterbor JW, et al. Longitudinal study of elbow and shoulder pain in youth baseball pitchers. Med Sci Sports Exerc. 2001;33(11):1803-1810.

11. McFarland EG, Wasik M. Epidemiology of collegiate baseball injuries. Clin J Sport Med. 1998;8(1):10-13.

12. Oberlander MA, Chisar MA, Campbell B. Epidemiology of shoulder injuries in throwing and overhead athletes. Sports Med Arthrosc. 2000;8(2):115-123.

13. Li X, Zhou H, Williams P, et al. The epidemiology of single season musculoskeletal injuries in professional baseball. Orthop Rev. 2013; 5(1):e3.

14. Fleisig GS, Weber A, Hassell N, Andrews JR. Prevention of elbow injuries in youth baseball pitchers. Curr Sports Med Rep. 2009;8(5): $250-254$.

15. Morrey BF, An KN. Articular and ligamentous contributions to the stability of the elbow joint. Am J Sports Med. 1983;11(5): 315-319.

16. Fleisig GS, Andrews JR, Dillman CJ, Escamilla RF. Kinetics of baseball pitching with implications about injury mechanisms. Am J Sports Med. 1995;23(2):233-239.

17. Dillman CJ, Smutz P, Werner S. Valgus extension overload in baseball pitching (abstract). Med Sci Sports Exerc. 1991;23(Suppl 4):S135.

18. Dillman CJ, Fleisig GS, Andrews JR. Biomechanics of pitching with emphasis upon shoulder kinematics. J Orthop Sports Phys Ther. 1993; 18(2):402-408.

19. Kim NR, Moon SG, Ko SM, Moon WJ, Choi JW, Park JY. MR imaging of ulnar collateral ligament injury in baseball players: value for predicting rehabilitation outcome. Eur J Radiol. 2011;80(3):e422-e426.

20. Cain EL Jr, Dugas JR, Wolf RS, Andrews JR. Elbow injuries in throwing athletes: a current concepts review. Am J Sports Med. 2003;31(4):621-635.

21. Panjabi MM, Yoldas E, Oxland TR, Crisco JJ 3rd. Subfailure injury of the rabbit anterior cruciate ligament. J Orthop Res. 1996;14(2):216-222. 
22. Provenzano PP, Heisey D, Hayashi K, Lakes R, Vanderby R Jr. Subfailure damage in ligament: a structural and cellular evaluation. J Appl Physiol (1985). 2002;92(1):362-371.

23. Wang V, Bucchieri J, Pollock R, et al. The effects of cyclic loads on the subfailure properties of the inferior glenohumeral ligament. ASME Bioeng Conf. 1997;35:137-138.

24. Petty DH, Andrews JR, Fleisig GS, Cain EL. Ulnar collateral ligament reconstruction in high school baseball players: clinical results and injury risk factors. Am J Sports Med. 2004;32(5):1158-1164.

25. Jobe FW, Nuber G. Throwing injuries of the elbow. Clin Sports Med. 1986;5(4):621-636.

26. Mulligan SA, Schwartz ML, Broussard MF, Andrews JR. Heterotopic calcification and tears of the ulnar collateral ligament: radiographic and MR imaging findings. AJR Am J Roentgenol. 2000;175(4): 1099-1102.

27. Fleisig GS, Andrews JR, Cutter GR, et al. Risk of serious injury for young baseball pitchers: a 10-year prospective study. Am J Sports Med. 2011;39(2):253-257

28. Olsen SJ 2nd, Fleisig GS, Dun S, Loftice J, Andrews JR. Risk factors for shoulder and elbow injuries in adolescent baseball pitchers. Am J Sports Med. 2006;34(6):905-912.

29. Escamilla RF, Barrentine SW, Fleisig GS, et al. Pitching biomechanics as a pitcher approaches muscular fatigue during a simulated baseball game. Am J Sports Med. 2007;35(1):23-33.

30. Karakolis T, Bhan S, Crotin RL. An inferential and descriptive statistical examination of the relationship between cumulative work metrics and injury in Major League Baseball pitchers. J Strength Cond Res. 2013; 27(8):2113-2118.

31. Bradbury JC, Forman SL. The impact of pitch counts and days of rest on performance among major-league baseball pitchers. J Strength Cond Res. 2012;26(5):1181-1187.

32. Bushnell BD, Anz AW, Noonan TJ, Torry MR, Hawkins RJ. Association of maximum pitch velocity and elbow injury in professional baseball pitchers. Am J Sports Med. 2010;38(4):728-732.

33. Hurd WJ, Jazayeri R, Mohr K, Limpisvasti O, ElAttrache NS, Kaufman KR. Pitch velocity is a predictor of medial elbow distraction forces in the uninjured high school-aged baseball pitcher. Sports Health. 2012;4(5): 415-418.

34. Post E, Laudner KG, McLoda TA, Wong R. Correlation of shoulder and elbow kinetics with ball velocity in collegiate baseball pitchers. J Athl Train. 2015;50(6):629-633.

35. Crotin RL, Bhan S, Karakolis T, Ramsey DK. Fastball velocity trends in short-season minor league baseball. J Strength Cond Res. 2013;27(8): 2206-2212.

36. Aguinaldo AL, Chambers H. Correlation of throwing mechanics with elbow valgus load in adult baseball pitchers. Am J Sports Med. 2009;37(10):2043-2048.

37. Solomito MJ, Garibay EJ, Woods JR, Õunpuu S, Nissen CW. Lateral trunk lean in pitchers affects both ball velocity and upper extremity joint moments. Am J Sports Med. 2015;43(5):1235-1240.

38. Oyama S, Goerger CP, Goerger BM, Lephart SM, Myers JB. Effects of non-assisted posterior shoulder stretches on shoulder range of motion among collegiate baseball pitchers. Athl Train Sport Health Care. 2010; 2(4):107-163.

39. Matsuo T, Escamilla RF, Fleisig GS, Barrentine SW, Andrews JR. Comparison of kinematic and temporal parameters between different pitch velocity groups. J Appl Biomech. 2001;17:1-13.

40. Wilson GJ, Elliott BC, Wood GA. Stretch shorten cycle performance enhancement through flexibility training. Med Sci Sports Exerc. 1992 24(1):116-123.

41. Grantham WJ, Iyengar JJ, Byram IR, Ahmad CS. The curveball as a risk factor for injury a systematic review. Sports Health. 2015;7(1):19-26.

42. Dines JS, Frank JB, Akerman M, Yocum LA. Glenohumeral internal rotation deficits in baseball players with ulnar collateral ligament insufficiency. Am J Sports Med. 2009;37(3):566-570.

43. Garrison JC, Cole MA, Conway JE, Macko MJ, Thigpen C, Shanley E. Shoulder range of motion deficits in baseball players with an ulnar collateral ligament tear. Am J Sports Med. 2012;40(11):2597-2603.
44. Wilk KE, Macrina LC, Fleisig GS, et al. Deficits in glenohumeral passive range of motion increase risk of elbow injury in professional baseball pitchers: a prospective study. Am J Sports Med. 2014;42(9): 2075-2081.

45. Burkhart SS, Morgan CD, Kibler WB. The disabled throwing shoulder: spectrum of pathology part I: pathoanatomy and biomechanics. Arthroscopy. 2003;19(4):404-420.

46. Reagan KM, Meister K, Horodyski MB, Werner DW, Carruthers C, Wilk K. Humeral retroversion and its relationship to glenohumeral rotation in the shoulder of college baseball players. Am J Sports Med. 2002;30(3):354-360.

47. Crockett HC, Gross LB, Wilk KE, et al. Osseous adaptation and range of motion at the glenohumeral joint in professional baseball pitchers. Am J Sports Med. 2002;30(1):20-26.

47. Hsu JE, Peng Q, Schafer DA, Koh JL, Nuber GW, Zhang LQ. In vivo three-dimensional mechanical actions of individual. J Appl Biomech. 2008;24(4):325-332.

48. Osbahr DC, Cannon DL, Speer KP. Retroversion of the humerus in the throwing shoulder of college baseball pitchers. Am J Sports Med. 2002;30(3):347-353.

49. Kronberg M, Brostrom LA, Soderlund V. Retroversion of the humeral head in the normal shoulder and its relationship to the normal range of motion. Clin Orthop Relat Res. 1990;(253):113-117.

50. Sabick MB, Kim YK, Torry MR, Keirns MA, Hawkins RJ. Biomechanics of the shoulder in youth baseball pitchers: implications for the development of proximal humeral epiphysiolysis and humeral retrotorsion. Am J Sports Med. 2005;33(11):1716-1722.

51. Noonan TJ, Shanley E, Bailey LB, et al. Professional pitchers with glenohumeral internal rotation deficit (gird) display greater humeral retrotorsion than pitchers without GIRD. Am J Sports Med. 2015;43(6): 1448-1454.

52. Hibberd EE, Oyama S, Myers JB. Increase in humeral retrotorsion accounts for age-related increase in glenohumeral internal rotation deficit in youth and adolescent baseball players. Am J Sports Med. 2014;42(4):851-858.

53. Pieper HG. Humeral torsion in the throwing arm of handball players. Am J Sports Med. 1998;26(2):247-253.

54. Whiteley R, Ginn K, Nicholson L, Adams R. Indirect ultrasound measurement of humeral torsion in adolescent baseball players and non-athletic adults: reliability and significance. J Sci Med Sport. 2006;9(4):310-318.

55. Anz AW, Bushnell BD, Griffin LP, Noonan TJ, Torry MR, Hawkins RJ. Correlation of torque and elbow injury in professional baseball pitchers. Am J Sports Med. 2010;38(7):1368-1374.

56. USA Baseball Medical and Safety Advisory Committee. Position Statement for Youth Baseball Pitchers. Durham, NC: USA Baseball Medical and Safety Advisory Committee; 2013.

57. Little League Baseball. Regular Season Pitching Rules-Baseball. Williamsport: Little League Baseball; 2010.

58. McNeil WF. The Evolution of Pitching in Major League Baseball. Jefferson, NC: McFarland and Company, Inc.; 2006.

59. Davis JT, Limpisvasti O, Fluhme D, et al. The effect of pitching biomechanics on the upper extremity in youth and adolescent baseball pitchers. Am J Sports Med. 2009;37(8):1484-1491.

60. Laudner KG, Sipes RC, Wilson JT. The acute effects of sleeper stretches on shoulder range of motion. J Athl Train. 2008;43(4):359-363.

61. Oyama S, Yu B, Blackburn JT, Padua DA, Li L, Myers JB. Effect of excessive contralateral trunk tilt on pitching biomechanics and performance in high school baseball pitchers. Am J Sports Med. 2013;41(10):2430-2438.

62. McClure P, Balaicuis J, Heiland D, Broersma ME, Thorndike CK, Wood A. A randomized controlled comparison of stretching procedures for posterior shoulder tightness. J Orthop Sports Phys Ther. 2007;37(3): $108-114$.

63. Wilk KE, Obma P, Simpson CD, Cain EL, Dugas JR, Andrews JR. Shoulder injuries in the overhead athlete. J Orthop Sports Phys Ther. 2009;39(2):38-54. 
64. Wilk KE, Yenchak AJ, Arrigo CA, Andrews JR. The advanced throwers ten exercise program: a new exercise series for enhanced dynamic shoulder control in the overhead throwing athlete. Phys Sportsmed. 2011;39(4):90-97.

65. Jiang JJ, Leland JM. Analysis of pitching velocity in major league baseball players before and after ulnar collateral ligament reconstruction. Am J Sports Med. 2014;42(4):880-885.

66. Wilk KE, Macrina LC, Cain EL, Dugas JR, Andrews JR. Rehabilitation of the Overhead Athlete's Elbow. Sports Health. 2012;4(5):404-414.

68. Lin F, Kohli N, Perlmutter S, Lim D, Nuber GW, Makhsous M. Muscle contribution to elbow joint valgus stability. J Shoulder Elbow Surg. 2007;16(6):795-802.

69. Udall JH, Fitzpatrick MJ, McGarry MH, Leba TB, Lee TQ. Effects of flexor-pronator muscle loading on valgus stability of the elbow with an intact, stretched, and resected medial ulnar collateral ligament. J Shoulder Elbow Surg. 2009;18(5):773-778.

70. Escamilla RF, Ionno M, deMahy MS, et al. Comparison of three baseballspecific 6-week training programs on throwing velocity in high school baseball players. J Strength Cond Res. 2012;26(7):1767-1781.

71. Carter AB, Kaminski TW, Douex AT Jr, Knight CA, Richards JG. Effects of high volume upper extremity plyometric training on throwing velocity and functional strength ratios of the shoulder rotators in collegiate baseball players. J Strength Cond Res. 2007;21(1):208-215.

72. Lust KR, Sandrey MA, Bulger SM, Wilder N. The effects of 6-week training programs on throwing accuracy, proprioception, and core endurance in baseball. J Sport Rehabil. 2009;18(3):407-426.

73. Axe M, Hurd W, Snyder-Mackler L. Data-based interval throwing programs for baseball players. Sports Health. 2009;1(2):145-153.

74. Dodson CC, Slenker N, Cohen SB, Ciccotti MG, DeLuca P. Ulnar collateral ligament injuries of the elbow in professional football quarterbacks. J Shoulder Elbow Surg. 2010;19(8):1276-1280.

75. Fleisig GS, Escamilla RF, Andrews JR, Matsuo T, Satterwhite Y, Barrentine SW. Kinematic and kinetic comparison between baseball pitching and football passing. J Appl Biomech. 1996;12:207-224.

76. Rettig AC, Sherrill C, Snead DS, Mendler JC, Mieling P. Nonoperative treatment of ulnar collateral ligament injuries in throwing athletes. $\mathrm{Am} \mathrm{J}$ Sports Med. 2001;29(1):15-17.

77. Furushima K, Itoh Y, Iwabu S. What are the risk factors for failure after conservative treatment of ulnar collateral ligament injuries of the elbow in baseball players? Orthop J Sport Med. 2013;1(4 Suppl):232.

78. Jobe FW, Stark H, Lombardo SJ. Reconstruction of the ulnar collateral ligament in athletes. J Bone Joint Surg Am. 1986;68(8):1158-1163.

79. Andrews JR, Jost PW, Cain EL. The ulnar collateral ligament procedure revisited: the procedure we use. Sports Health. 2012;4(5): $438-441$.

80. Smith GR, Altchek DW, Pagnani MJ, Keeley JR. A muscle-splitting approach to the ulnar collateral ligament of the elbow. Neuroanatomy and operative technique. Am J Sports Med. 1996;24(5):575-580.

81. Rohrbough JT, Altchek DW, Hyman J, Williams RJ 3rd, Botts JD. Medial collateral ligament reconstruction of the elbow using the docking technique. Am J Sports Med. 2002;30(4):541-548.

82. Dines JS, Altchek DW, editors. Elbow Ulnar Collateral Ligament Injury: A Guide to Diagnosis and Treatment. New York: Springer Science + Business Media; 2015.
83. Watson JN, McQueen P, Hutchinson MR. A systematic review of ulnar collateral ligament reconstruction techniques. Am J Sports Med. 2014;42(10):2510-2516.

84. Vitale MA, Ahmad CS. The outcome of elbow ulnar collateral ligament reconstruction in overhead athletes: a systematic review. Am J Sports Med. 2008;36(6):1193-1205.

85. Cain EL Jr, Andrews JR, Dugas JR, et al. Outcome of ulnar collateral ligament reconstruction of the elbow in 1281 athletes: results in 743 athletes with minimum 2-year follow-up. Am J Sports Med. 2010; 38(12):2426-2434.

86. Dodson CC, Thomas A, Dines JS, Nho SJ, Williams RJ 3rd, Altchek DW. Medial ulnar collateral ligament reconstruction of the elbow in throwing athletes. Am J Sports Med. 2006;34(12):1926-1932.

88. Paletta GA Jr, Klepps SJ, Difelice GS, et al. Biomechanical evaluation of 2 techniques for ulnar collateral ligament reconstruction of the elbow. Am J Sports Med. 2006;34(10):1599-1603.87. Regan WD, Korinek SL, Morrey BF, An KN. Biomechanical study of ligaments around the elbow joint. Clin Orthop Relat Res. 1991;271: 170-179.

89. Prud'homme J, Budoff JE, Nguyen L, Hipp JA. Biomechanical analysis of medial collateral ligament reconstruction grafts of the elbow. Am J Sports Med. 2008;36(4):728-732.

90. Savoie FH 3rd, Morgan C, Yaste J, Hurt J, Field L. Medial ulnar collateral ligament reconstruction using hamstring allograft in overhead throwing athletes. J Bone Joint Surg Am. 2013;95(12):1062-1066.

91. Bernas GA, Ruberte Thiele RA, Kinnaman KA, Hughes RE, Miller BS, Carpenter JE. Defining safe rehabilitation for ulnar collateral ligament reconstruction of the elbow: a biomechanical study. Am J Sports Med. 2009;37(12):2392-2400.

92. Stodden DF, Fleisig GS, McLean SP, Andrews JR. Relationship of biomechanical factors to baseball pitching velocity: within pitcher variation. J Appl Biomech. 2005;21(1):44-56.

93. Seroyer ST, Nho SJ, Bach BR, Bush-Joseph CA, Nicholson GP, Romeo AA. The kinetic chain in overhand pitching: its potential role for performance enhancement and injury prevention. Sports Health. 2010;2(2):135-146.

94. Reinold MM, Wilk KE, Reed J, Crenshaw K, Andrews JR. Interval sport programs: guidelines for baseball, tennis, and golf. $J$ Orthop Sports Phys Ther. 2002;32(6):293-298.

95. Erickson BJ, Gupta AK, Harris JD, et al. Rate of return to pitching and performance after Tommy John surgery in major league baseball pitchers. Am J Sports Med. 2014;42(3):536-543.

96. Fleisig GS, Leddon CE, Laughlin WA, et al. Biomechanical performance of baseball pitchers with a history of ulnar collateral ligament reconstruction. Am J Sports Med. 2015;43(5):1045-1050.

97. Dines JS, Yocum LA, Frank JB, ElAttrache NS, Gambardella RA, Jobe FW. Revision surgery for failed elbow medial collateral ligament reconstruction. Am J Sports Med. 2008;36(6):1061-1065.

98. Jones KJ, Conte S, Patterson N, ElAttrache NS, Dines JS. Functional outcomes following revision ulnar collateral ligament reconstruction in Major League Baseball pitchers. J Shoulder Elbow Surg. 2013;22(5): 642-646.
Open Access Journal of Sports Medicine

\section{Publish your work in this journal}

Open Access Journal of Sports Medicine is an international, peer-reviewed, open access journal publishing original research, reports, reviews and commentaries on all areas of sports medicine. The manuscript management system is completely online and includes a very quick and fair peer-review system.

\section{Dovepress}

Visit http://www.dovepress.com/testimonials.php to read real quotes from published authors. 